\title{
MedChemComm
}

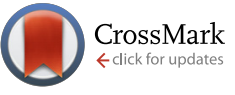

Cite this: Med. Chem. Commun., 2016, 7, 464

Received 2nd October 2015, Accepted 29th November 2015

www.rsc.org/medchemcomm
DOI: $10.1039 / c 5 m d 00451 a$

\section{A potent trifluoromethyl ketone histone deacetylase inhibitor exhibits class-dependent mechanism of action}

\begin{abstract}
Andreas S. Madsen and Christian A. Olsen*
Histone deacetylase (HDAC) enzymes are validated targets for treatment of certain cancers and have potential as targets for pharmacological intervention in a number of other diseases. Thus, inhibitors of these enzymes have received considerable attention, but these are often evaluated by $I C_{50}$ value determination, which may vary significantly depending on assay conditions. In this work, we therefore performed detailed kinetic evaluation of inhibitors containing two fundamentally different zinc-binding chemotypes, hydroxamic acid or trifluoromethyl ketone. For the hydroxamic acids, a fast-on-fast-off mechanism was observed, but the trifluoromethyl ketone compound exhibited differential mechanisms depending on the enzyme isoform. The trifluoromethyl ketone compound displayed a fast-on-fast-off mechanism against class-Ila HDACs 4 and 7, but slow-binding mechanisms against class-I and class-llb enzymes (HDACs 1-3, 6 and 8). Furthermore, different competitive, slow-binding mechanisms were observed for HDACs 1, 2, and 6 vs. HDACs 3 and 8, demonstrating the power of kinetic experiments for characterisation of enzyme inhibitors.
\end{abstract}

\section{Introduction}

The $\mathrm{Zn}^{2+}$-dependent histone deacetylase (HDAC) enzymes catalyse hydrolytic removal of acetyl functionalities from $\varepsilon$-amino groups of lysine residues in a variety of proteins including histones. ${ }^{1}$ Posttranslational modification (PTM) plays major roles in regulation of protein function, and histone acetylation affects chromatin packing and recruitment of transcription factors resulting in effects on gene expression. ${ }^{2,3}$ Recent discoveries have underpinned lysine acetylation as a general PTM in proteins, ${ }^{4}$ and a growing list of non-histone proteins are identified as substrates for the HDACs, ${ }^{5-8}$ thereby extending their potential impact on cellular function. ${ }^{2,3,9,10}$ Eleven HDAC isoforms are encoded by the human genome, classified according to sequence similarity: ${ }^{11}$ class-I (HDACs 1-3 and 8), class-IIa (HDACs 4, 5, 7 and 9), class-IIb (HDACs 6 and 10), and class-IV (HDAC11).

Due to the importance of HDACs in a wide variety of disease states, ${ }^{12-15}$ selective HDAC inhibitors have potential as tool compounds and possibly as novel drugs. Several chemotypes have been described as HDAC inhibitors with the most extensively studied class being inhibitors featuring the strongly zinc-chelating hydroxamic acid moiety, ${ }^{16,17}$ including vorinostat (SAHA, 1) and trichostatin A (2) (Fig. 1).

Center for Biopharmaceuticals and Department of Drug Design \& Pharmacology, University of Copenhagen, Universitetsparken 2, DK-2100, Copenhagen, Denmark. E-mail: cao@sund.ku.dk
Due to the strong metal ion-chelating propensity of hydroxamic acids, inhibitors containing this functionality have been suspected to give rise to off-target effects, but recent experiments have indicated that this may be of minor concern. ${ }^{18,19}$ Nevertheless, hydroxamic acids have also been associated with rapid degradation and clearance, and investigation of other zinc-binding functionalities, such as thiols (as in romidepsin (3)), ${ }^{20}$ trifluoromethyl ketones $(4),^{21-24}$ and $o$-aminoanilides $(5)^{25,26}$ (Fig. 1), may therefore be of interest.

The binding mode of hydroxamic acids, which are generally considered potent class-I, -IIb and -IV inhibitors, but much poorer class-IIa inhibitors, ${ }^{27}$ is through bidentate coordination to the active site $\mathrm{Zn}^{2+}$ ion via the carbonyl oxygen and deprotonated nitrogen-bound oxygen atom. ${ }^{28}$

Trifluoromethyl ketones constitute another strongly zincbinding functionality. This motif is readily hydrated in aqueous solution ${ }^{29}$ and presumably binds to the active site $\mathrm{Zn}^{2+}$ ion via bidentate coordination from the two resulting geminal hydroxy groups. ${ }^{30}$ Although trifluoromethyl ketones have also been reported to be metabolically labile by reduction to the corresponding alcohol in vivo, ${ }^{21}$ they may give rise to interesting tool compounds for investigation of HDAC inhibition in vitro. Interestingly, compounds containing this zincbinding group have been reported to selectively inhibit classIIa HDAC isoforms; ${ }^{22,23,31}$ however, class-IIa inhibition does not appear to be an inherent capacity of the functional group itself. $^{32}$ We recently reinvestigated the inhibitory properties of a known trifluoromethyl ketone compound $(4)^{21}$ and 
<smiles>O=C(CCCCCCC(=O)Nc1ccccc1)NO</smiles>

1) vorinostat (SAHA)<smiles>CC(/C=C/C(=O)NO)=C\C(C)C(=O)c1ccc(N(C)C)cc1</smiles>

2) trichostatin $A(T S A)$

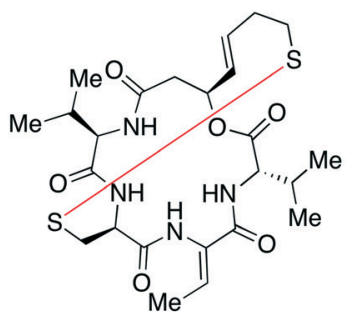

3) romidepsin (FK-228)<smiles>O=C(CCCCCCC(=O)C(F)(F)F)Nc1ccccc1</smiles>

4<smiles>Cc1ccc(NC(=O)CCCCCC(=O)Nc2ccccc2N)cc1</smiles>

5) pimelic diphenylamide 106

Fig. 1 Structures of selected HDAC inhibitors.

extended the previous studies to characterization of its inhibitory effect against all eleven zinc-dependent HDACs, ${ }^{32}$ thereby identifying compound $\mathbf{4}$ as a promising inhibitor of isozymes from all four HDAC classes. ${ }^{32}$ In our previous study, $\mathrm{IC}_{50}$ and $K_{\mathrm{i}}$ values were determined from standard endpoint dose-response assays assuming a fast-on-fast-off binding mechanism. In these experiments, the HDAC enzyme and fluorogenic substrate are incubated with varying concentrations of inhibitor for $1 \mathrm{~h}$, followed by assay development by addition of trypsin to achieve fluorophore release. Thus, a constant rate over the entire incubation period has to be assumed in order to apply the ChengPrusoff equation for approximation of the corresponding $K_{\mathrm{i}}$ values.

While endpoint assays are convenient for screening large numbers of inhibitors, more information can be obtained from kinetic inhibition experiments, where progression of enzyme activity is monitored over time. By applying such assays, Gottesfeld and co-workers demonstrated that pimelic diphenylamide 106 (5), an $o$-aminoanilide based class-I HDAC inhibitor, inhibits HDACs 1-3 via different mechanisms not revealed by simple $\mathrm{IC}_{50}$ determination. They were instead able to show that compound 5 is a slow, tight-binding inhibitor of HDACs 1-3, but acting via a different mechanism for HDACs 1 and 2 compared to HDAC $3 .^{26}$ More recently, two groups have also reported on the development of kinetically selective HDAC2 inhibitors based on $o$-aminoanilide moieties, and considering differences in the active sites of HDACs $1-3 .^{33,34}$

Interestingly, trifluoromethyl ketones have previously been described as slow-binding inhibitors for serine proteases, ${ }^{29,35,36}$ and we therefore found it interesting to perform a more elaborate investigation of the inhibitory mechanism of compound 4 on the different HDAC isoforms. We have previously used continuous rate experiments for investigating inhibitors of the $\mathrm{NAD}^{+}$-dependent deacylase sirtuin $5^{37}$ as well as cyclic peptide HDAC inhibitors ${ }^{38}$ and thought we could modify those protocols for evaluation of compound 4 in continuous assays against a selection of the zincdependent HDACs.

Not surprisingly, our investigation showed that the hydroxamic acid-containing inhibitors acted via a fast-onfast-off binding mechanism against all the tested enzymes.
For the trifluoromethyl ketone inhibitor, on the other hand, the mechanism of inhibition proved to vary between enzyme isoforms. Thus, this study provides valuable mechanistic insight for future medicinal chemistry efforts involving HDAC inhibitors containing this zinc-binding group.

\section{Results and discussion}

Initially, we investigated the influence of preincubation of HDAC 3 and trifluoromethyl ketone 4 on the determined $\mathrm{IC}_{50}$ values and found a 17 -fold increase in apparent inhibitor potency at $2 \mathrm{~h}$ of preincubation time (Fig. 2). Further incubation lead to substantial decrease in enzyme activity, even without addition of inhibitor, thus precluding prolonged preincubation due to enzyme degradation in the assay buffer. This initial observation prompted us to investigate the kinetics of HDAC inhibition in more detail.

Usually, the equilibrium of inhibitor binding to enzyme is assumed to be rapidly obtained, i.e., fast on and off rates for the enzyme-inhibitor equilibrium, which is therefore obtained prior to onset of the experiment. For this fast-onfast-off mechanism, linear progression curves are observed when monitoring product formation continuously, and the enzyme-inhibitor equilibrium constant $\left(K_{\mathrm{i}}\right)$ can be determined by fitting a secondary plot of the relative rates $\left(v_{\mathrm{i}} / v_{\mathrm{o}}\right)$ to eqn (1), where $v_{\mathrm{i}}$ and $v_{\mathrm{o}}$ are the observed rates with and without inhibitor, respectively.



Fig. 2 Residual activity of HDAC3 after preincubation with trifluoromethyl ketone 4. Preincubation times and apparent $I C_{50}$ values are shown. 


$$
\frac{v_{\mathrm{i}}}{v_{\mathrm{o}}}=\left(\frac{[\mathrm{I}]}{K_{\mathrm{i}}\left(1+\frac{[\mathrm{S}]}{K_{\mathrm{m}}}\right)}+1\right)^{-1}
$$

However, if the enzyme-inhibitor equilibrium is slow and thus not obtained prior to onset of the experiment, nonlinear progression curves will be obtained. In such an event, the slow, competitive binding of inhibitor may be divided into two mechanisms as shown in Fig. 3. In mechanism A, the enzyme-inhibitor complex forms without kinetically observable intermediates, whereas in mechanism B, an equilibrium is rapidly established with an initial complex, which is then converted to a second stable complex displaying ratedetermining kinetics.

For both types of slow binding kinetics, product formation follows eqn (2), where $[\mathrm{P}]$ is the concentration of product at time $t$. The $v_{\mathrm{o}}$ and $v_{\mathrm{s}}$ are the initial and final steady-state velocities, respectively, and $k_{\text {obs }}$ is the apparent first-order rate constant for establishment of the enzyme-inhibitor equilibrium. It should be noted, that for the fast-on-fast-off mechanism, $[\mathrm{P}]=$ $v_{\mathrm{s}} t$ is the limiting case of mechanism A when $k_{\text {obs }}$ is very large.

$$
[\mathrm{P}]=v_{\mathrm{s}} t+\frac{v_{\mathrm{o}}-v_{\mathrm{s}}}{k_{\mathrm{obs}}}\left(1-\mathrm{e}^{-k_{\mathrm{obs}} t}\right)
$$

For mechanisms $\mathrm{A}$ and $\mathrm{B}$, the relationship between $k_{\mathrm{obs}}$ and [I] is linear (eqn (3)) and hyperbolic (eqn (4)), respectively. As a result, fitting of these equations to secondary plots of the $k_{\mathrm{obs}}-[\mathrm{I}]$ relationship allows determination of the binding mechanism, as well as calculation of the rate constants involved and the resulting enzyme-inhibitor equilibrium constants $\left[K_{\mathrm{i}}\right.$ for mechanism A (eqn (5)) and $K_{\mathrm{i}, 1}$ and $K_{\mathrm{i}}$ for mechanism B (eqn (6) and (7), respectively)].

Slow binding, mechanism A

$$
\begin{gathered}
k_{\mathrm{obs}}=k_{1}\left(1+\frac{[\mathrm{S}]}{K_{\mathrm{m}}}\right)[\mathrm{I}]+k_{-1} \\
K_{\mathrm{i}}=\frac{k_{-1}}{k_{\mathrm{l}}}
\end{gathered}
$$

Slow binding, mechanism B

$$
\begin{gathered}
k_{\mathrm{obs}}=\frac{k_{2}}{[\mathrm{I}]+\frac{k_{-1}}{k_{\mathrm{l}}}\left(1+\frac{[\mathrm{S}]}{K_{\mathrm{m}}}\right)}[\mathrm{I}]+k_{-2} \\
K_{\mathrm{i}, 1}=\frac{k_{-1}}{k_{1}} \\
K_{\mathrm{i}}=\frac{k_{-1} k_{-2}}{k_{1}\left(k_{2}+k_{-2}\right)}=K_{\mathrm{i}, 1} \frac{k_{-2}}{\left(k_{2}+k_{-2}\right)}
\end{gathered}
$$

To determine the inhibitory mechanism and associated kinetic values, we initially established assay conditions that

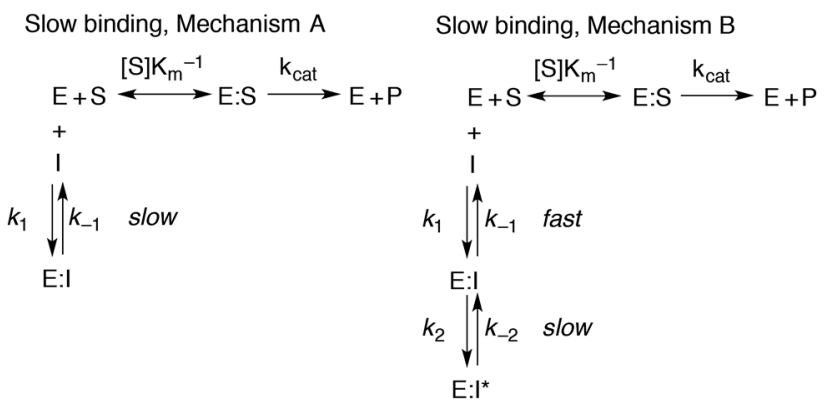

Fig. 3 Mechanism of slow inhibitor binding with the corresponding rate constants.

allowed monitoring of enzyme activity for $60 \mathrm{~min}$. Progression curves were generated by incubating the enzyme-inhibitor combination with an appropriate fluorogenic substrate at concentrations greater than the $K_{\mathrm{m}}$ [Ac-LGK ac $^{-A M C}(20 \mu \mathrm{M})$ for HDACs $1-3$ and $6\left(K_{\mathrm{m}}\right.$ values $6 \mu \mathrm{M}, 3 \mu \mathrm{M}, 6 \mu \mathrm{M}$, and 16 $\mu \mathrm{M}$, respectively), Ac-LGK $\mathrm{tfa}$-AMC $(50 \mu \mathrm{M})$ for HDACs 4 and 7 ( $K_{\mathrm{m}}$ values $12 \mu \mathrm{M}$ and $26 \mu \mathrm{M}$, respectively), and Ac- $\mathrm{RHK}_{\mathrm{ac}} \mathrm{K}_{\mathrm{ac}}{ }^{-}$ AMC $(400 \mu \mathrm{M})$ for HDAC8 $\left(K_{\mathrm{m}}\right.$ value $\left.\left.430 \mu \mathrm{M}\right)\right]$. The trypsin concentration was optimised to be high enough to ensure rapid establishment of steady state by cleaving the AMC fluorophore from the deacylated peptide intermediate at a rate that avoids lag time. At the same time, the trypsin concentration should be low enough to ensure a linear progress curve for $60 \mathrm{~min}$ without observable reduction of HDAC activity in the experiment without inhibitor added. Previously, Gottesfeld and co-workers reported low stability of HDAC8 under the employed conditions. ${ }^{26}$ In agreement with this, we also observed rapid loss of activity of HDAC8 when incubated in the standard Tris buffer. However, changing the buffer to either the buffer marketed for HDAC8 (a Tris buffer containing PEG $_{8 \mathrm{kDa}}$ ) or the buffer described by Bradner, Mazitschek and co-workers (a HEPES buffer, data not shown), ${ }^{27}$ allowed monitoring of HDAC8 activity for $60 \mathrm{~min}$ as well.

Having established suitable conditions for all the investigated enzymes, a series of progress curves were generated for HDACs 1-4 and 6-8 against the three investigated inhibitors (1, 2 and 4).

SAHA (1) has previously been demonstrated to be a poor class-IIa inhibitor ${ }^{32}$ and was not included for HDACs 4 and 7 . Instead, TSA was chosen as the hydroxamic acid inhibitor against class-IIa HDACs and HDAC3 was chosen as the representative for TSA inhibition of class-I HDACs. All seven HDACs were included for investigation of compound 4.

Hydroxamate inhibitors such as SAHA have been reported to display fast-on-fast-off kinetics against class-I HDACs, ${ }^{26}$ and in agreement with these reports, linear progress curves were obtained for inhibition of HDACs 1-3 and 8 as well as the class-IIb enzyme HDAC6 when monitored for $1 \mathrm{~h}$ (Fig. 4). Low nanomolar inhibition constants were observed for all investigated enzymes except for HDAC8 $(230 \pm 20 \mathrm{nM}$; Table 1$)$, and all values are in agreement with the literature. ${ }^{27}$ Simi- $^{-}$ larly, linear progress curves were obtained for TSA inhibition 

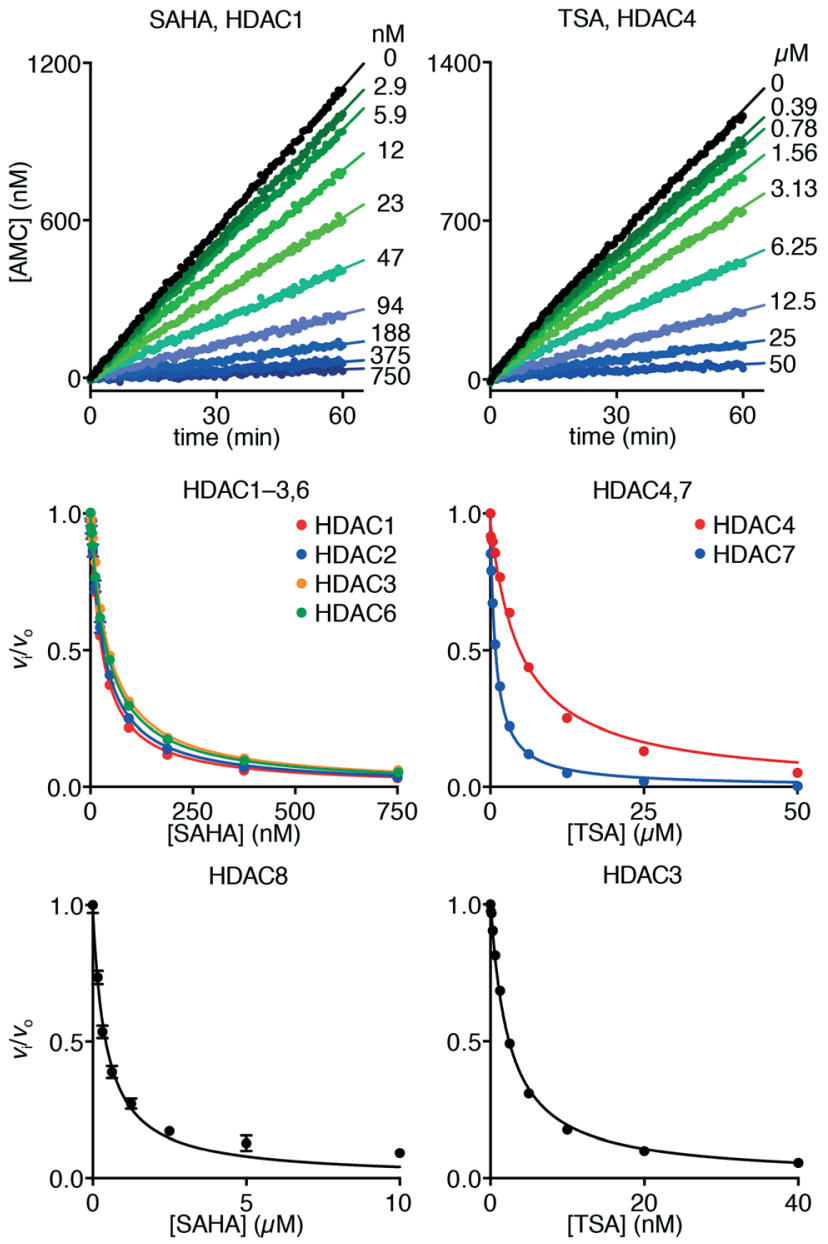

Fig. 4 Progress curves of HDAC1 ( $\left(\mathrm{LGK}_{\mathrm{ac}}\right)$ and HDAC4 (LGK $\left.\mathrm{tfa}_{\mathrm{a}}\right)$ deacylase activities under SAHA and TSA inhibition, respectively. Relative rates $\left(v_{\mathrm{i}} / v_{\mathrm{o}}\right)$, fitted to eqn (1), for HDACs $1-3$ and $6\left(\mathrm{LGK}_{\mathrm{ac}}\right)$, and HDAC8 $\left(\mathrm{RHK}_{\mathrm{ac}} \mathrm{K}_{\mathrm{ac}}\right)$ against concentrations of SAHA and HDACs 3, 4 and 7 ( LGK $\left._{\text {tfa }}\right)$ against concentrations of TSA.

of all investigated enzymes, including class-IIa enzymes HDAC4 and HDAC7 (Fig. 4). Despite a marked span of potencies of almost 2000 -fold $(0.54 \pm 0.02 \mathrm{nM} v s .980 \pm 80 \mathrm{nM}$ for HDACs 3 and 4, respectively), these results indicate that faston-fast-off kinetics is general for hydroxamate mediated HDAC inhibition regardless of enzyme class and potency.

Interestingly, trifluoromethyl ketone 4 displayed a differential inhibition mechanism depending on enzyme class. Thus compound 4 was found to be a potent inhibitor of class-IIa enzymes displaying a fast-on-fast-off mechanism with $K_{\mathrm{i}}$ values of $5.1 \pm 0.2 \mathrm{nM}$ and $4.7 \pm 0.1 \mathrm{nM}$ against HDACs 4 and 7, respectively (Fig. 5).

In contrast, compound 4 displayed slow binding kinetics with non-linear progression curves when incubated with all the investigated class-I and class-IIb enzymes. The obtained progression curves were fitted to eqn (2) and secondary plots of the calculated $k_{\text {obs }}$ values against inhibitor concentration were created (Fig. 5). For HDACs 1, 2 and 6, a linear relationship was observed, consistent with competitive, slow-binding of the inhibitor following mechanism A, and the data were therefore fitted to eqn (3) to determine the kinetic parameters. The overall inhibition constants $\left(K_{\mathrm{i}}\right)$ were determined to be $9.8 \mu \mathrm{M}, 11 \mu \mathrm{M}$ and $4.5 \mu \mathrm{M}$, respectively. For HDACs 1 and 6 , these are in good agreement with our previous findings using endpoint experiments, while the $K_{\mathrm{i}}$ value against HDAC2 is $\sim 30$-fold higher than the previously determined. ${ }^{32}$ The overall trend that HDACs 4 and 7 are significantly more potently inhibited than HDACs 1, 2 and 6, however, corresponds well with previous findings.

For HDACs 3 and 8, on the other hand, a hyperbolic relationship between $k_{\mathrm{obs}}$ and inhibitor concentration was indicated, which is consistent with competitive, slow binding of the inhibitor following mechanism B. Thus, fitting of the data to eqn (4) allowed determination of the accompanying kinetic parameters (Table 2). For HDAC3 the overall inhibition constant $\left(K_{\mathrm{i}}\right)$ was estimated to be $11 \mathrm{nM}$ and the overall inhibition constant $\left(K_{\mathrm{i}}\right)$ for HDAC8 was estimated to be 33 $\mathrm{nM}$, which is in the range of inhibition constants for class-IIa HDACs 4 and 7. For HDAC3, the $K_{\mathrm{i}}$ value is an order of magnitude lower than previously estimated from endpoint experiments using the Cheng-Prusoff equation, ${ }^{32}$ which may be explained by a low $k_{-2}$ value indicating a highly stable enzyme-inhibitor complex (E:I*, Fig. 3 mechanism B). This also helps explain the data obtained by preincubation experiments discussed above (Fig. 2), and underlines the power of kinetic evaluation of inhibitors that do not follow standard fast-on-fast-off mechanism of action.

Interestingly, potent inhibition of HDACs 3, 4, 7 and 8 by trifluoromethyl ketone 4 correlates well with the observation that these enzymes all efficiently cleave $\varepsilon-N$-trifluoroacetylated lysine substrates. ${ }^{39}$ Furthermore, the lower affinities for compound 4 against HDACs 1,2 and 6 also agree with the low detrifluoroacetylase activities of these enzymes. Taken together, these observations suggest that certain HDACs accommodate the trifluoromethyl group better than others, and that this feature is not in accordance with isoform sub-classification.

\section{Conclusions}

In summary, we have evaluated hydroxamate and trifluoromethyl ketone HDAC inhibitors by continuous assays monitoring the progress of substrate conversion over time to enable kinetic insight. We selected enzymes from class-I (HDACs 1-3 and 8), class-IIa (HDACs 4 and 7), and class-IIb (HDAC6), and as

Table $1 K_{\mathrm{i}}$ values (nM) for HDAC inhibition by SAHA (1) and TSA (2)

\begin{tabular}{lllllll}
\hline & HDAC1 & HDAC2 & HDAC3 & HDAC8 & HDAC6 & HDAC4 \\
\hline 1 & $6.4 \pm 0.2$ & $4.2 \pm 0.1$ & $9.9 \pm 0.3$ & $230 \pm 20$ & $17.7 \pm 0.3$ & HDAC7 \\
2 & n.d. & n.d. & $0.54 \pm 0.02$ & $200 \pm 20$ & n.d. & n.d. \\
& & & & & $980 \pm 80$ & $300 \pm 10$
\end{tabular}



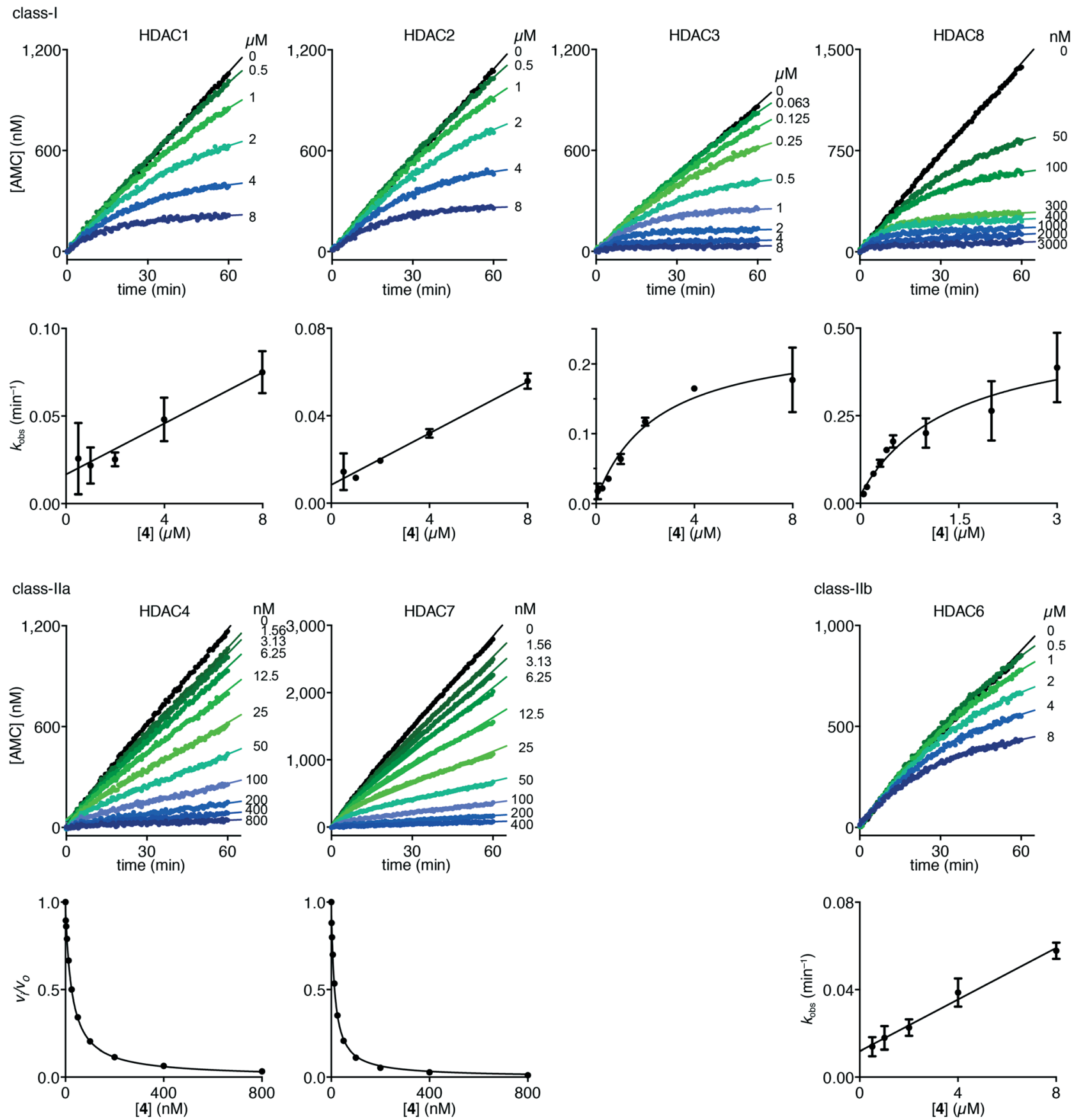

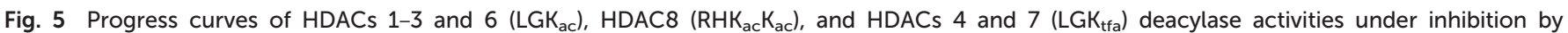
trifluoromethyl ketone 4. Apparent first-order rate constants ( $\left.k_{\text {obs }}\right)$ for trifluoromethyl ketone 4 inhibition were fitted to eqn (3) for HDACs 1,2 and $6\left(\mathrm{LGK}_{\mathrm{ac}}\right)$ or eqn (4) for HDAC3 and relative rates $\left(v_{\mathrm{i}} / v_{\mathrm{o}}\right)$ were fitted to eqn (1) for HDACs 4 and 7.

Table 2 Kinetic values and inhibition constants for HDAC inhibition by trifluoromethyl ketone 4

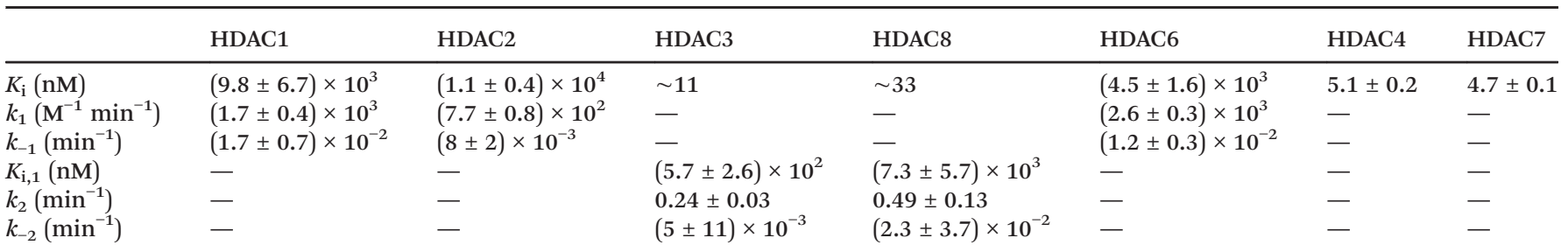


suspected based on literature precedent, the hydroxamic acids all exhibited a fast-on-fast-off mechanism of inhibition. However, the SAHA-inspired trifluoromethyl ketone (4) only displayed a fast-on-fast-off mechanism against HDACs 4 and 7, whereas slow-binding mechanisms were observed against class-I and class-IIb enzymes (HDACs 1-3, 6 and 8). Furthermore, a more detailed investigation revealed similar mechanisms for HDACs 1 , 2 , and 6, which were different from the mechanism exhibited against HDACs 3 and 8. This insight is important for understanding the effects of trifluoromethyl ketone containing inhibitors, and should be taken into account when designing novel chemotypes containing this moiety. Furthermore, it will be interesting to investigate the possible effects of these mechanistic differences as well as kinetics of ketone reduction in cellular environments.

\section{Experimental}

\section{Materials}

HDAC1, HDAC2, HDAC3-NCoR1, HDAC6 and HDAC8 were purchased from Enzo Life Sciences (Postfach, Switzerland). HDAC4 and HDAC7 were purchased from Millipore (Upstate, Temecula, CA). The HDAC assay buffers used were: Buffer A, Biomol International BML-KI-143 [Tris/Cl (50 mM), NaCl (137 $\mu \mathrm{M}), \mathrm{KCl}(2.7 \mu \mathrm{M}), \mathrm{MgCl}_{2}(1 \mu \mathrm{M}), \mathrm{pH}$ 8.0] with BSA $(0.5 \mathrm{mg}$ $\mathrm{mL}^{-1}$ ) added; or Buffer B, Biomol International BML-KI-311 [Tris/Cl (50 mM), NaCl (137 $\mu \mathrm{M}), \mathrm{KCl}(2.7 \mu \mathrm{M}), \mathrm{MgCl}_{2}(1 \mu \mathrm{M})$, PEG-8 kDa (10\% w/v), pH 8.0] with BSA (0.5 mg mL $\left.{ }^{-1}\right)$ added. Trichostatin A and trypsin (10 000 units per mg, TPCK treated from bovine pancreas) were from Sigma-Aldrich (Steinheim, Germany), and syntheses of SAHA and compound 4 were previously reported. ${ }^{32}$ All chemicals and solvents were of analytical grade and were used without further purification as obtained from commercial suppliers.

\section{Fluorescence measurements}

All microtiter plates were analysed using a Perkin Elmer EnSpire plate reader with excitation at $360 \mathrm{~nm}$ and detecting emission at $460 \mathrm{~nm}$. Fluorescence measurements (RFU) were converted to [AMC] concentrations based on an [AMC]-fluorescence standard curve and all data analysis were performed using GraphPad Prism.

\section{Fluorescence-based preincubation inhibition experiments}

Hydrolase activity of HDAC3-NCoR1 against substrate Ac-LGK $\mathrm{ac}^{-}$ AMC was evaluated under varying concentrations of trifluoromethyl ketone 4 and preincubation times. HDAC3 (1000 pg $\mu \mathrm{L}^{-1}$, $10 \mu \mathrm{L}$ ) was added to a solution of trifluoromethyl ketone 4 (30 $\mu \mathrm{L}$ total volume, $16.7 \mu \mathrm{M}-167 \mathrm{pM}, 10$-fold dilution) at $37{ }^{\circ} \mathrm{C}$ (final concentrations $250 \mathrm{pg} \mu \mathrm{L}^{-1}$ and $12.5 \mu \mathrm{M}-125 \mathrm{pM}$, respectively) with preincubation times of $2 \mathrm{~h}, 1 \mathrm{~h}, 30 \mathrm{~min}$, $15 \mathrm{~min}$ and $0 \mathrm{~min}$, then a solution of Ac-LGK $\mathrm{ac}^{-\mathrm{AMC}}(10 \mu \mathrm{L}$, $50 \mu \mathrm{M}$ ) was added to each well and the plate was incubated for additional $30 \mathrm{~min}$ at $37^{\circ} \mathrm{C}$ (final concentrations HDAC3: $200 \mathrm{pg} \mu \mathrm{L}^{-1}, 4: 10 \mu \mathrm{M}-100 \mathrm{pM}$, and Ac-LGK $\mathrm{ac}^{-\mathrm{AMC}}$ : $10 \mu \mathrm{M}$, respectively). Then a solution of trypsin $\left(50 \mu \mathrm{L}, 0.4 \mathrm{mg} \mathrm{mL} \mathrm{m}^{-1}\right)$ was added and the reaction mixture was developed for $15 \mathrm{~min}$ before analysing fluorescence. The resulting data were analysed to obtain residual enzymatic activity relative to control wells.

\section{Fluorescence-based steady-state rate inhibition experiments}

Hydrolase activities of HDACs against substrates Ac-LGK $\mathrm{ac}^{-}$ $\mathrm{AMC}, \mathrm{Ac}-\mathrm{LGK}_{\mathrm{tfa}}-\mathrm{AMC}$ and $\mathrm{Ac}-\mathrm{RHK}_{\mathrm{ac}} \mathrm{K}_{\mathrm{ac}}$-AMC were evaluated under varying concentrations of SAHA (1), TSA (2), and trifluoromethyl ketone 4. The HDAC enzyme was incubated with the relevant substrate, inhibitor, and trypsin in a total volume of $100 \mu \mathrm{L}$ of assay buffer (Buffer A, except for HDAC8, where Buffer $\mathrm{B}$ was used), using the following concentrations: HDAC1 (2500 pg $\left.\mu \mathrm{L}^{-1}\right), \mathrm{LGK}_{\mathrm{ac}}(20 \mu \mathrm{M})$, trypsin $\left(3 \mathrm{ng} \mu \mathrm{L}^{-1}\right)$; HDAC2 (4000 pg $\left.\mu \mathrm{L}^{-1}\right), \mathrm{LGK}_{\mathrm{ac}}(20 \mu \mathrm{M})$, trypsin $\left(3 \mathrm{ng} \mu \mathrm{L}^{-1}\right)$; HDAC3-NCoR1 (200 pg $\left.\mu \mathrm{L}^{-1}\right), \mathrm{LGK}_{\mathrm{ac}}(20 \mu \mathrm{M})$, trypsin $(3 \mathrm{ng}$ $\left.\mu \mathrm{L}^{-1}\right)$; HDAC4 (50 pg $\left.\mu \mathrm{L}^{-1}\right)$, LGK $_{\mathrm{tfa}}(50 \mu \mathrm{M})$, trypsin $(5 \mathrm{ng}$ $\left.\mu \mathrm{L}^{-1}\right)$; HDAC6 (4000 pg $\left.\mu \mathrm{L}^{-1}\right), \mathrm{LGK}_{\mathrm{ac}}(20 \mu \mathrm{M})$, trypsin $(3 \mathrm{ng}$ $\left.\mu \mathrm{L}^{-1}\right)$; HDAC7 $\left(2.5 \mathrm{pg} \mu \mathrm{L}^{-1}\right), \mathrm{LGK}_{\mathrm{tfa}}(50 \mu \mathrm{M})$, trypsin $(5 \mathrm{ng}$ $\left.\mu \mathrm{L}^{-1}\right)$; HDAC8 $\left(5 \mathrm{pg} \mu \mathrm{L}^{-1}\right), \mathrm{LGK}_{\mathrm{tfa}}(200 \mu \mathrm{M})$, trypsin $(3 \mathrm{ng}$ $\left.\mu \mathrm{L}^{-1}\right)$; HDAC8 (400 pg $\left.\mu \mathrm{L}^{-1}\right), \mathrm{RHK}_{\mathrm{ac}} \mathrm{K}_{\mathrm{ac}}(400 \mu \mathrm{M})$, trypsin $(5 \mathrm{ng}$ $\left.\mu \mathrm{L}^{-1}\right)$. In situ fluorophore release was monitored immediately by fluorescence readings recorded continuously every 10-15 seconds for $60 \mathrm{~min}$ at $25^{\circ} \mathrm{C}$. Using GraphPad Prism, background fluorescence was subtracted and the data were fitted to the relevant equations $\left([\mathrm{P}]=v_{\mathrm{s}} t\right.$, or eqn (2)). Secondary plots were then fitted to the relevant equations (eqn (1), (3) or (4)) to obtain the desired kinetic parameters.

\section{Acknowledgements}

Financial support from the Lundbeck Foundation (Young Group Leader Fellowship, C. A. O.), the Danish Independent Research Council-Natural Sciences (Steno grant no. 10080907, C. A. O.), the Danish Independent Research CouncilTechnical and Production Sciences (Sapere Aude grant no. 12132328, A. S. M.), and the Carlsberg Foundation (equipment grant, C. A. O.) is gratefully acknowledged.

\section{Notes and references}

1 T. Kouzarides, Cell, 2007, 128, 693-705.

2 M. Biel, V. Wascholowski and A. Giannis, Angew. Chem., Int. Ed., 2005, 44, 3186-3216.

3 M. Haberland, R. L. Montgomery and E. N. Olson, Nat. Rev. Genet., 2009, 10, 32-42.

4 C. Choudhary, C. Kumar, F. Gnad, M. L. Nielsen, M. Rehman, T. C. Walther, J. V. Olsen and M. Mann, Science, 2009, 325, 834-840.

5 M. D. Hirschey, Cell Metab., 2011, 14, 718-719.

6 C. A. Olsen, ChemMedChem, 2014, 9, 434-437.

7 C. A. Olsen, Angew. Chem., Int. Ed., 2012, 51, 3755-3756.

8 C. Choudhary, B. T. Weinert, Y. Nishida, E. Verdin and M. Mann, Nat. Rev. Mol. Cell Biol., 2014, 15, 536-550.

9 S. Zhao, W. Xu, W. Jiang, W. Yu, Y. Lin, T. Zhang, J. Yao, L. Zhou, Y. Zeng, H. Li, Y. Li, J. Shi, W. An, S. M. Hancock, F. 
He, L. Qin, J. Chin, P. Yang, X. Chen, Q. Lei, Y. Xiong and K. L. Guan, Science, 2010, 327, 1000-1004.

10 Q. Wang, Y. Zhang, C. Yang, H. Xiong, Y. Lin, J. Yao, H. Li, L. Xie, W. Zhao, Y. Yao, Z. B. Ning, R. Zeng, Y. Xiong, K. L. Guan, S. Zhao and G. P. Zhao, Science, 2010, 327, 1004-1007.

11 I. V. Gregoretti, Y. M. Lee and H. V. Goodson, J. Mol. Biol., 2004, 338, 17-31.

12 S. Minucci and P. G. Pelicci, Nat. Rev. Cancer, 2006, 6, 38-51.

13 J. E. Bolden, M. J. Peart and R. W. Johnstone, Nat. Rev. Drug Discovery, 2006, 5, 769-784.

14 P. A. Cole, Nat. Chem. Biol., 2008, 4, 590-597.

15 M. Paris, M. Porcelloni, M. Binaschi and D. Fattori, J. Med. Chem., 2008, 51, 1505-1529.

16 F. F. Wagner, M. Weïwer, M. C. Lewis and E. B. Holson, Neurotherapeutics, 2013, 10, 589-604.

17 P. Bertrand, Eur. J. Med. Chem., 2010, 45, 2095-2116.

18 Y. Chen and S. M. Cohen, ChemMedChem, 2015, 10, 1733-1738.

19 J. A. Day and S. M. Cohen, J. Med. Chem., 2013, 56, 7997-8007.

20 R. Furumai, A. Matsuyama, N. Kobashi, K. H. Lee, M. Nishiyama, H. Nakajima, A. Tanaka, Y. Komatsu, N. Nishino, M. Yoshida and S. Horinouchi, Cancer Res., 2002, 62, 4916-4921.

21 R. R. Frey, C. K. Wada, R. B. Garland, M. L. Curtin, M. R. Michaelides, J. L. Li, L. J. Pease, K. B. Glaser, P. A. Marcotte, J. J. Bouska, S. S. Murphy and S. K. Davidsen, Bioorg. Med. Chem. Lett., 2002, 12, 3443-3447.

22 P. Jones, M. J. Bottomley, A. Carfí, O. Cecchetti, F. Ferrigno, P. Lo Surdo, J. M. Ontoria, M. Rowley, R. Scarpelli, C. Schultz-Fademrecht and C. Steinkühler, Bioorg. Med. Chem. Lett., 2008, 18, 3456-3461.

23 M. J. Bottomley, P. Lo Surdo, P. Di Giovine, A. Cirillo, R. Scarpelli, F. Ferrigno, P. Jones, P. Neddermann, R. de Francesco, C. Steinkühler, P. Gallinari and A. Carfí, J. Biol. Chem., 2008, 283, 26694-26704.

24 M. Ilies, D. P. Dowling, P. M. Lombardi and D. W. Christianson, Bioorg. Med. Chem. Lett., 2011, 21, 5854-5858.
25 A. Saito, T. Yamashita, Y. Mariko, Y. Nosaka, K. Tsuchiya, T. Ando, T. Suzuki, T. Tsuruo and O. Nakanishi, Proc. Natl. Acad. Sci. U. S. A., 1999, 96, 4592-4597.

26 C. J. Chou, D. Herman and J. M. Gottesfeld, J. Biol. Chem., 2008, 283, 35402-35409.

27 J. E. Bradner, N. West, M. L. Grachan, E. F. Greenberg, S. J. Haggarty, T. Warnow and R. Mazitschek, Nat. Chem. Biol., 2010, 6, 238-243.

28 M. S. Finnin, J. R. Donigian, A. Cohen, V. M. Richon, R. A. Rifkind, P. A. Marks, R. Breslow and N. P. Pavletich, Nature, 1999, 401, 188-193.

29 K. N. Allen and R. H. Abeles, Biochemistry, 1989, 28, 8466-8473.

30 T. K. Nielsen, C. Hildmann, D. Riester, D. Wegener, A. Schwienhorst and R. Ficner, Acta Crystallogr., Sect. F: Struct. Biol. Cryst. Commun., 2007, 63, 270-273.

31 E. Muraglia, S. Altamura, D. Branca, O. Cecchetti, F. Ferrigno, M. V. Orsale, M. C. Palumbi, M. Rowley, R. Scarpelli, C. Steinkühler and P. Jones, Bioorg. Med. Chem. Lett., 2008, 18, 6083-6087.

32 A. S. Madsen, H. M. Kristensen, G. Lanz and C. A. Olsen, ChemMedChem, 2014, 9, 614-626.

33 F. F. Wagner, Y. L. Zhang, D. M. Fass, N. Joseph, J. P. Gale, M. Weïwer, P. McCarren, S. L. Fisher, T. Kaya, W. N. Zhao, S. A. Reis, K. M. Hennig, M. Thomas, B. C. Lemercier, M. C. Lewis, J. S. Guan, M. P. Moyer, E. Scolnick, S. J. Haggarty, L. H. Tsai and E. B. Holson, Chem. Sci., 2015, 6, 804-815.

34 J. Zhou, M. Li, N. Chen, S. Wang, H. B. Luo, Y. Zhang and R. Wu, ACS Chem. Biol., 2015, 10, 687-692.

35 K. Brady and R. H. Abeles, Biochemistry, 1990, 29, 7608-7617.

36 M. H. Gelb, J. P. Svaren and R. H. Abeles, Biochemistry, 1985, 24, 1813-1817.

37 A. S. Madsen and C. A. Olsen, J. Med. Chem., 2012, 55, 5582-5590.

38 J. S. Villadsen, B. Kitir, K. Wich, T. Friis, A. S. Madsen and C. A. Olsen, Med. Chem. Commun., 2014, 5, 1849-1855.

39 A. S. Madsen and C. A. Olsen, Angew. Chem., Int. Ed., 2012, 51, 9083-9087. 